\section{Fake news}

\section{Seek knowledge, not the truth}

Sir, I read with interest the article on fake news, ${ }^{1}$ specifically related to dentistry, and I tend to agree, to an extent, with the author that this area needs addressing. As the article correctly states the publication of the 'truth' can be manipulated because 'truth' is only one-third of credible knowledge, according to Plato, the ancient Greek philosopher. ${ }^{2,3}$

In fact, knowledge is about more than just the truth and actually contains another two parts, which is explored in epistemology. Thus, teaching dental students epistemology, inside education, is the only way I feel to fight this wave of inaccurate knowledge distribution that we are currently seeing.

Therefore, I propose the dental community embraces epistemology and learns 'how to use' knowledge, which is made up of three elements. This will give dental professionals, when doubt exists, the skills needed to establish what is credible knowledge and what is 'fake'.

As an educational supervisor attempting to teach elements of epistemology to my trainees, ${ }^{4}$ this discussion on fake news can only be a good thing.

D. Martin, Nottingham, UK

\section{References}

1. Dias da Silva M A, Walmsley A D. Fake news and dental education. Br Dent J 2019; 226: 397-399.

2. Stanford Encyclopedia of Philosophy. Plato on Knowledge in the Theaetetus. Published 7 May 2005; revised 13 December 2013. Available at https://plato.stanford.edu/ entries/plato-theaetetus/ (accessed 8 May 2019).

3. Stanford Encyclopedia of Philosophy. Fall 2013 edition. The Analysis of Knowledge. Published 6 February 2001; revised 15 November 2012. Available at https://plato. stanford.edu/archives/fall2013/entries/knowledge-analysis/ (accessed 8 May 2019).

4. Martin D. Development of a guided reflection tool to use after simulated medical emergency training. Sheffield Hallam University, 2016.

DOI: $10.1038 / s 41415-019-0380-x$

\section{Oral health}

\section{Copper water swishing}

Sir, we have read Dr Dagher and Dr Hannan's letter about mouthwash in the recent issue of your journal. ${ }^{1}$ They have suggested restriction of mouthwash advertisements or limiting mouthwash use with prescription only as use of mouthwash influences oral and general health. ${ }^{1}$

Dr Singh and colleagues have suggested that copper may help to prevent Streptococcus mutans infection in the oral cavity., ${ }^{2,3}$

Mouthwash use is also associated with a slight increase in blood pressure and risk of head and neck cancer. ${ }^{4,5}$ Copper present in drinking water stored in copper tanks kills bacteria and the copper content in drinking water stored in copper pots is within the permissible limits $(177 \pm 16 \mathrm{ppb})$ of the World Health Organisation. ${ }^{6}$ Hence swishing of drinking water stored in a copper tank may be a help as a safe economical mouthwash which can be used by the general population.

M. V. Math, Y. R. Kattimani, R. M. Khadkikar, Mumbai, India by email

\section{References}

1. Dagher A, Hannan N. Mouthwash: more harm than good? Br Dent J 2019; 226: 240.

2. Singh $K$, Senadheera D B, Levesque C M, Cvitkovitch D $G$. The copYAZ operon functions in copper efflux, biofilm formation, genetic transformation, and stress tolerance in Streptococcus mutans. J Bacteriol 2015; 197: 2545-2557.

3. Afseth J, Oppermann R V, Rølla G. Accumulation of Cu and $\mathrm{Zn}$ in human dental plaque in vivo. Caries Res 1983; 17: 310-314.

4. Kapil V, Haydar S M, Pearl V, Lundberg J O, Weitzberg E, Ahluwalia A. Physiological role for nitrate-reducing oral bacteria in blood pressure control. Free Radic Biol Med 2013; 55: 93-100.

5. Boffetta P, Hayes R B, Sartori S et al. Mouthwash use and cancer of the head and neck: a pooled analysis from the International Head and Neck Cancer Epidemiology Consortium. Eur J Cancer Prev 2016; 25: 344-348.

6. Sudha V B, Ganesan S, Pazhani G P, Ramamurthy T, Nair $G B$, Venkatasubramanian P. Storing drinking-water in copper pots kills contaminating diarrhoeagenic bacteria. J Health Popul Nutr 2012; 30: 17-21.

DOI: $10.1038 / s 41415-019-0381-9$

\section{Pharmaceuticals}

\section{Drugs in breastmilk}

Sir, while consideration is readily given to the dental treatment of pregnant patients, lesser thought is given to the impact on post-partum breastfeeding. Although there is the potential for drugs to cross the placenta in pregnancy, in breastfeeding the infant is delivered a direct dose of the drug that they are then required to metabolise and excrete themselves. Most adverse effects of medications in breastmilk occur in newborns under two months and rarely in those older than six months. ${ }^{1}$

This letter has come about from our experiences within an emergency dental clinic, where selecting the safest agent is vital in maintaining the nursing mother's oral health while caring for the breastfed infant's general health.

During the recent pulpal extirpation of a breastfeeding patient with irreversible pulpitis, we were surprised to find that the commonly used endodontic paste, Ledermix, is contraindicated for use in lactating patients. Ledermix contains demeclocycline, a tetracycline antibiotic that is excreted into breastmilk causing anti-anabolic and teratogenic effects - noticeably including deposits in bones and teeth. ${ }^{2}$ Odontopaste is also advised to be used 'with caution' in lactation as its active antibiotic ingredient, clindamycin, has been shown to be present in breastmilk and can have effects on the infant's gastrointestinal flora. ${ }^{3}$ As these endodontic medicaments contain active antibiotics associated with complications in overall infant and/or dental development, it is wise for the health of patient and child, and from a medico-legal stance, to use a more appropriate dressing: calcium hydroxide is safe for use in children and those who are pregnant or breastfeeding.

Admittedly in the field of dentistry, the amounts of medicaments used are usually small and unlikely to cause an adverse effect. However, as we have identified, there are those that remain an issue (further examples in Table 1) and caution should be given for those new mothers who may present in pain to both primary and secondary care dental services.

O. Barratt, E. Brewer, Cardiff, UK

\section{References}

1. Hotham N, Hotham E. Drugs in breastfeeding. Aust Prescr 2015; 38:156-159.

2. Health Products Regulatory Authority. Ledermix For Dental Use. 2015. Available at https://www.hpra.ie/homepage/medicines/ medicines-information/find-a-medicine/results/ item?pano=PA1321/002/001\&t=Ledermix $\% 20$ for $\% 20$ Dental\%20Use (accessed 8 May 2019)

3. NICE. British National Formulary. 2019. Available at https://bnf.nice.org.uk (accessed May 2019).

4. World Health Organisation. Breastfeeding and materna medication: Recommendations for drugs in the eleventh WHO model list of essential drugs. 2002. Available at https://www.who.int/maternal_child_adolescent/ documents/55732/en/ (accessed 16 March 2019).

DOI: $10.1038 / 541415-019-0382-8$
Table 1 Emergency dental materials/drugs and breastfeeding ${ }^{3,4}$

\begin{tabular}{l|l|l}
\hline Safe in usual dosages & Use with caution & Contraindicated \\
\hline Lidocaine with adrenaline & Odontopaste & Ledermix \\
Paracetamol & Ibuprofen & Amalgam \\
Chlorhexidine mouthwash & Midazolam & Metronidazole \\
Penicillin antibiotics (eg & Dexamethasone & Tetracycline antibiotics (eg \\
Amoxicillin) & Co-amoxiclav & Doxycycline) \\
Erythromycin & Clindamycin & Quinolone antibiotics (eg \\
Prednisolone & Aciclovir & Ciprofloxacin) \\
Betamethasone & Miconazole & Codeine phosphate \\
\hline
\end{tabular}

